\title{
A ODISSEIA SEGUNDO PENÉLOPE, POR MARGARET ATWOOD
}

\author{
Daniela Silva de Freitas ${ }^{1 \times}$
}

${ }^{1}$ Universidade Federal de Alfenas, Alfenas, MG, Brasil

\begin{abstract}
Resumo
Este artigo analisa a re-visão que Margaret Atwood faz da Odisseia em A odisseia de Penélope (2005). Partimos de Bakhtin (1993) para mapear a subversão dos traços constitutivos do épico operada pela versão de Penélope e vemos como, ao destronar Odisseu e dar voz a Penélope e às doze servas enforcadas no retorno de Ulisses a Ítaca, Atwood rompe com a linguagem épica sagrada, desmistifica a lenda e atualiza o passado épico absoluto, oferecendo, no lugar da narrativa grandiosa, a experiência pessoal e privada da vida das mulheres. Em seguida, analisamos algumas das implicações da reescrita do mito homérico por uma escritora canadense contemporânea e argumentamos que, ao matar Homero enquanto autor, Atwood tanto inscreve sua obra no cânone quanto abre espaço para o reconhecimento de outras versões da história.
\end{abstract}

Palavras-chave: Re-visão; Cânone; Escritora mulher

\section{THE ODYSSEY ACCORDING TO PENELOPE, BY MARGARET ATWOOD}

\begin{abstract}
:
This article analyses how Margaret Atwood re-views The Odyssey in The Penelopiad (2000). In order to do so, we use Bakhtin (1993) to map the ways in which Penelope's version of The Odyssey subverts the main traces of the epic. By dethroning Odysseus and giving voice to Penelope and the servants killed upon Ulysses's return to Ithaca, Atwood breaks with the sacred language of the epic, demythologizes the legend and updates the absolute past of the epic world, offering an account concerning the personal private lives of women. We also analyze the context of production and some of the implications of a Canadian contemporary woman writer's rewriting of the Homeric myth. We argue that, by killing Homer as author, Atwood both inscribes her work in the canon and makes room for other stories.

Keywords: Re-vision; Canon; Woman writer
\end{abstract}

\footnotetext{
“Doutora em Literatura, Cultura e Contemporaneidade pela Pontifícia Universidade Católica do Rio de Janeiro, com período sanduíche na Universidade do Novo México. Mestra em Literaturas de Língua Inglesa e graduada em Letras: Inglês/Literaturas pela Universidade do Estado do Rio de Janeiro. Atualmente é professora de literaturas de língua inglesa na Universidade Federal de Alfenas. Tem interesse por literaturas e culturas contemporâneas e debates acerca das questões de nação, raça, gênero e suas interseccionalidades. Seu e-mail é: danielasf@gmail.com. ORCID: https://orcid.org/0000-0002-2670-3244.
} 
A odisseia de Penélope é o romance que Margaret Atwood (2005b) fez sob a encomenda da Myth Series, um projeto que, segundo ela, foi idealizado por quatro editores do Reino Unido, Canadá, Estados Unidos e Alemanha durante uma das Feiras do Livro de Frankfurt. A ideia, explica Atwood (2005a), em um artigo intitulado "The Myth Series and Me", era pedir a escritores de diferentes partes do mundo para recontar um mito, qualquer mito, cada um do seu jeito e na sua língua, em mais ou menos cem páginas. A série inclui publicações de autores de diferentes nacionalidades que recontam histórias, mitos e lendas de origens grega, nórdica, japonesa, chinesa, irlandesa, amazônica, suméria, eslava, entre outras. O site antigo do projeto afirmava que "mitos são histórias universais e atemporais que refletem e moldam nossas vidas - exploram nossos desejos, nossos medos, nossos anseios, e oferecem narrativas que nos lembram do que significa ser humanos" (ABOUT..., s.l, n/p, minha tradução').

Tal definição do mito é bem diferente daquela oferecida por Roland Barthes em algumas de suas obras. Em Mitologias, Barthes define o mito como uma "linguagem", ou "um abuso ideológico" (BARTHES, 2001, p. 7). Em O rumor da língua, ele afirma que o mito é uma transformação do cultural em natural, através de um processo de naturalização no qual um conjunto de crenças, práticas e costumes são vistos como algo da ordem da natureza e não do social:

O mito consiste em inverter a cultura em natureza, ou pelo menos o social, o cultural, o ideológico, o histórico em "natural": aquilo que não passa de produto da divisão de classes e das suas sequelas morais, culturais, estéticas é apresentado (enunciado) como óbvio por natureza (BARTHES, 2004, p. 76).

Na introdução de A odisseia de Penélope, Margaret Atwood, por sua vez, afirma que nunca poderemos recuperar o significado exato dos mitos para os seus públicos na antiguidade. Contudo, de forma pós-moderna e ambígua, ao mesmo tempo cúmplice e questionadora, a autora declara que podemos continuar usando os mitos - como eles já foram usados com tanta frequência no passado - como pedras fundamentais para novas leituras, dotando-os de novos significados dentro de um novo contexto de espaço e tempo (ATWOOD, 2005a).

Partindo dessas discussões acerca do mito, este artigo propõe uma análise da re-visão que Margaret Atwood faz da Odisseia - grande mito da filosofia universal, traduzido e celebrado com tanta frequência por grandes autores da literatura de língua inglesa desde o século XVI - em A odisseia de Penélope. Começaremos argumentando que, ao reler Homero, Atwood subverte os traços constitutivos do gênero épico e desconstrói a grande narrativa do herói ao dar voz a Penélope e às doze servas enforcadas por Ulisses no seu retorno a Ítaca. Em seguida, ensaiaremos algumas considerações acerca das implicações decorrentes da reescrita do mito homérico por uma escritora mulher canadense contemporânea.

Em "Epos e romance" - ensaio cujo título original era "O romance como gênero literário" - Mikhail Bakhtin (1993) tenta mapear as características do romance enquanto gênero literário. Bakhtin afirma que grande parte da dificuldade 
dessa empreitada se dá porque, diferentemente dos grandes gêneros do passado, rigidamente definidos e detalhadamente caracterizados em poéticas como as de Aristóteles, Horácio e Boileau, o romance é mais jovem que a escritura e o livro, e concebido para a recepção silenciosa da leitura. O romance, diz o autor, é cria da era moderna, é um gênero ainda em formação, cuja ossatura não se encontra consolidada. Sua forma moderna e permeável antecipa a futura evolução de toda literatura e contribui para a renovação de todos os gêneros, contaminando-os com a sua evolução.

Buscando um caminho para iniciar sua caracterização, Bakhtin (1993) se volta para as definições normativas oferecidas pelos próprios fazedores do gênero, os romancistas. A partir de uma série de obras, ele depreende um conjunto de quatro exigências-teses acerca do romance, dentre as quais está a tese de que o romance deve ser para o mundo contemporâneo aquilo que a epopeia foi para o mundo antigo. Enquanto afirma que essas exigências não constituem em si uma teoria do romance, esse autor afirma que essas teses apontadas podem ser consideradas como um dos vértices da tomada de consciência do romance. Oferecidas sob uma constante ênfase na maleabilidade e na versatilidade do gênero, essas definições são complementadas por três particularidades fundamentais do romance: sua tridimensão estilística e sua consciência plurilíngue; a transformação das coordenadas temporais de suas representações literárias; e sua área de estruturação da imagem literária, que apresenta contato máximo com o presente a partir do seu aspecto inacabado. Depois de brevemente explicar a primeira particularidade, Bakhtin (1993) afirma que as duas últimas se tornam particularmente evidentes a partir da comparação do romance e da epopeia. É a partir desse ponto que o teórico nomeia os três traços constitutivos da epopeia: o passado absoluto; a lenda nacional; e a distância épica absoluta, que isola o mundo épico do tempo do autor e de seus ouvintes.

Quanto ao primeiro deles, o passado absoluto, Bakhtin (1993) afirma que, na antiguidade, o passado não se apresentava como algo relativo, textualmente e coletivamente construído, já que, para os antigos, era a memória, e não o conhecimento, a principal faculdade criadora da literatura. Tais atribuições conferem ao passado sua inquestionabilidade e sacralizam a tradição. O passado absoluto se interliga à lenda nacional, que faz referência à forma sob a qual o discurso épico é sempre enunciado. Sobre a lenda nacional, esse autor afirma que:

O mundo épico do passado absoluto, por sua própria natureza, é inacessível à experiência individual e não admite pontos de vista e apreciações pessoais. Não se pode vê-lo, senti-lo, tocá-lo, não pode ser considerado sob nenhum ponto de vista, não se pode experimentá-lo, analisá-lo, mostrá-lo ou penetrar nas suas entranhas. Ele é dado somente enquanto lenda, sagrada e peremptória, que envolve uma apreciação universal e exige uma atitude de reverência para consigo (BAKHTIN, 1993, p.408).

O mundo épico não pode ser modificado, reinterpretado e nem reavaliado, defende Bakhtin. Ele está pronto e concluído, e é imutável, tanto em sua realida- 
de quanto em seu sentido e valor. É a partir dessa rigidez de versões, sentidos e valores que também se define o terceiro traço, a distância épica absoluta, a partir da qual o mundo épico "adquire sua perfeição excepcional", que também impede questionamentos ou refutações (BAKHTIN, 1993, p. 409).

Justamente o que Atwood (2005b) faz em seu romance, argumentamos, é penetrar nas entranhas do passado sagrado e inquestionável do mito homérico para mostrar que, por mais que ele se articule discursivamente como universal, peremptório e absoluto - por mais que a Odisseia tenha se articulado dessa maneira por quase trinta séculos, durante cinco dos quais, ela foi traduzida, reescrita e celebrada repetidas vezes pelos grandes poetas da literatura inglesa -, ainda assim o mito exprime um ponto de vista, que a linguagem épica tenta naturalizar. Ao eleger novas narradoras, ao focar a narrativa em novas personagens e ao lançar luz sobre insterstícios, lacunas e ausências de versões da Odisseia anteriores à sua, Atwood revela e destaca a natureza construída do discurso do mito. Isso é feito a partir de uma série de operações que se dão em diversos níveis do romance, que se evidenciam tanto na estrutura do romance - sua instabilidade genérica, a heteroglossia de suas vozes narrativas, os textos iniciais e finais do romance, nos quais ouvimos diretamente a voz da autora - quanto no nível da caracterização das personagens, dos seus diálogos, suas falas e suas ações.

Uma ocasião em que o passado tem seu caráter relativo denunciado é o décimo segundo capítulo de A Odisseia de Penélope. Em "Espera", Penélope nos conta sobre os rumores que ouviu das naus que passavam por Ítaca, enquanto aguardava o retorno de Ulisses após a guerra de Tróia:

Odisseu enfrentara um gigante ciclope de um olho só, segundo alguns; nada disso, foi só um taberneiro caolho, disse outro, com quem brigou por causa da conta. Alguns de seus homens teriam sido devorados por canibais, alguns diziam; não, foi só uma escaramuça normal, alegavam outros, com narizes sangrando, mordidas na orelha, facadas e eviscerações. Odisseu residia numa ilha encantada, como hóspede de uma deusa, diziam alguns; ela transformara seus marinheiros em porcos - nenhuma proeza nisso, na minha opinião - e os transformara novamente em homens depois de se apaixonar por Odisseu e alimentá-lo com iguarias extravagantes preparadas por suas próprias mãos divinas, e os dois deliravam ao fazer amor todas as noites; que nada, diziam outros, era só um puteiro chique e ele tomava dinheiro da cafetina.

Desnecessário dizer, os menestreis abordavam os temas e os complementavam consideravelmente. Sempre cantavam a versão mais nobres na minha presença - na qual Odisseu era protegido pelas deusas, criativo, bravo, expedito e enfrentava monstros sobrenaturais. A única razão que o impedia de voltar para casa era um deus - Posídon, deus do mar, segundo alguns - inimigo dele, pois o ciclope abatido por Odisseu seria seu filho. Ou havia vários deuses furiosos com ele. Ou outra coisa. Com certeza os menestreis enfatizavam, por adulação - só um poder divino superior poderia evitar que meu marido voltasse correndo o mais rápido possível para os amorosos - e adoráveis - braços da esposa.

Quanto mais eles caprichavam nessa parte, mais caros eram os presentes devidos por mim. E eu sempre os recompesava. Até uma invenção óbvia serve para reconfortar um pouco, na falta de opções (ATWOOD, 2005b, n.p.). 
"Difícil saber em quem acreditar" afirma Penélope, perto do final do capítulo (ATWOOD, 2005b, n. p.). O caráter não reverencial da atitude de Penélope quanto ao passado dessacraliza a memória épica ao nos mostrar que a versão do que ocorreu de verdade pode variar de acordo com quem conta, para quem conta e com que intenção. Assim, vemos como a natureza do assunto - bem como do tempo e do espaço - tratado por Atwood são muito diferentes daqueles que seriam típicos de uma epopeia. No trecho acima, Ulisses não é representado como um grande herói, símbolo da nação, mas como um homem cujas grandes qualidades e grandes feitos são questionados. O espaço da ação em A odisseia de Penélope, ao invés de se estender pela vasta geografia da nação, se passa em espaços privados da vida de Penélope: no castelo de seus pais, no castelo de Ulisses, nos campos de Asfódelo. Ao invés da grande narrativa da lenda nacional, o romance de Atwood (2005b) encena a experiência individual e pessoal de Penélope, que nos é contada a partir de seu próprio ponto de vista.

Ponto de vista esse que tem sua confiabilidade constantemente desestabilizada pela outra voz narrativa: a linha de coro composta pelas doze servas que foram enforcadas por Ulisses em sua chegada a Ítaca, cuja narração entrecorta aquela de Penélope. As vozes das servas tanto atestam e aconselham, quanto complementam a versão de Penélope, trazendo à tona aquilo que a narrativa de Penélope ignora, dissimula ou falha em recontar. "Incluí um Coro que canta, dança e declama, em homenagem aos Coros da tragédia grega. A convenção de zombar da ação principal já estava presente nas peças satíricas, representadas com as tragédias sérias", afirma a autora nas notas finais do romance (ATWOOD, 2005b, n.p.).

Só que, apesar de preservar algumas das características clássicas, essas servas não são um coro grego propriamente, mas uma linha de coro típica de musicais e, como tal, elas cantam, dançam e encenam sua própria versão da história. Dentre os vinte e nove capítulos do livro, onze são narrados pela linha de coro. O foco de tais capítulos, declara a autora na introdução do livro, recai sobre "duas questões que se destacam numa leitura atenta da Odisseia: o motivo do enforcamento das servas e o real propósito de Penélope". A história contada na Odisseia, continua Atwood, apresenta "muitas incoerências. Sempre vivi assombrada pelas escravas enforcadas; em A odisseia de Penélope, o mesmo acontece com Penélope" (ATWOOD, 2005b, n. p.).

Além de perturbar o conteúdo da narrativa principal, questionando a verdade da história contada por Penélope, os capítulos das servas também representam uma quebra na forma do romance. Cada um deles tem uma forma diferente, que pertenceria mais aos gêneros líricos e dramáticos do que propriamente ao épico (ou narrativo): uma canção para pular corda, um lamento, uma canção popular, uma pastoral, uma canção de trabalho de marinheiros (a sea shanty, nomeada na tradução em português de "nau precária"), uma balada, um drama, uma aula de antropologia, uma gravação do julgamento de Odisseu, uma canção de amor e uma despedida (um envoi, no original em inglês).

Em seu primeiro capítulo, o segundo do romance, elas se apresentam: 


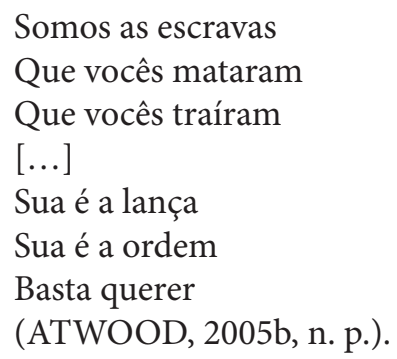

Enquanto, no terceiro capítulo, Penélope nos conta de sua infância, no quarto capítulo, as servas nos contam sobre as delas:

Também éramos crianças. Também nascemos dos pais errados. De pais pobres, pais escravos, pais camponeses e pais servos; pais que nos venderam, pais de quem nos roubaram. Nossos pais não eram deuses, não eram semideuses, não eram ninfas nem nereidas. Fomos servir no palácio, desde pequenas; trabalhávamos duramente, dia e noite, desde pequenas. Quando chorávamos, ninguém enxugava nossas lágrimas. Se dormíssemos, nos acordavam a pontapés. Diziam que não tínhamos pai nem mãe. Diziam que éramos vadias. Diziam que éramos sujas. Nós éramos sujas. A sujeira era nossa preocupação, nossa responsabilidade, nossa especialidade, nossa culpa (ATWOOD, 2005b, n. p.).

No oitavo capítulo, elas também nos contam sobre como foram crianças com Telêmaco: "Quando ele era criança,/ Éramos seus brinquedos e mascotes, irmãs de araque, magras companhias./ Crescemos enquanto ele crescia [...]" (ATWOOD, 2005b, n. p.). Contam sobre como elas não tinham escolha e tinham sempre que atender a todos os desejos de seus amos e seus hóspedes.

As servas escrevem para não serem esquecidas, conforme elas mesmas gritam no vigésimo sexto capítulo, sobre o julgamento de Ulisses, quando ele está prestes a ser considerado inocente pelo juiz por ter matado os pretendentes: "Vocês se esqueceram de nós! E o nosso caso? Não podem soltá-lo! Fomos enforcadas a sangue frio! Doze de nós! Por nada!" (ATWOOD, 2005b, n.p.). Ao que o juiz responde:

Juiz (consultando um livro: a Odisseia): Está escrito aqui, neste livro - um livro que precisamos consultar, pois é a principal referência para este caso - embora possua inegáveis tendências aéticas e contenha excesso de sexo e violência, na minha opinião - está dito bem aqui - vamos ver - rapsódia XXII, que as servas foram violentadas. Os pretendentes as violentaram. Ninguém os impediu de fazer isso. Ademais, as escravas, pelo que consta, foram obrigadas pelos pretendentes a servi-los em seus propósitos hediondos e revoltantes. Seu cliente sabia de tudo - consta que ele mesmo declarou isso. Portanto, as escravas foram subjugadas e estavam totalmente desprotegidas. Isso é correto? (ATWOOD, 2005b, n. p.).

O uso de um volume de a Odisseia como evidência legal válida contra Ulisses denota a importância que o mito apresenta em nossa sociedade. Em seguida, o juiz chama Penélope como testemunha, que tenta se esquivar da responsabilidade: "Eu estava dormindo, meritíssimo. Durmo muito" (ATWOOD, 2005b, n. p.). 
Contudo, é a própria Penélope quem nos conta, no décimo quinto capítulo, sobre como ela incentivava suas doze servas a dormirem com os pretendentes, para que elas os espiassem de perto:

Vocês devem fingir paixão por esses homens. Se acharem que vocês passaram para o lado deles, confiarão em vocês e descobriremos seus planos. É um jeito de vocês servirem a seu senhor, e ele se mostrará muito grato quando retornar (ATWOOD, 2005b, n. p.).

A versão das servas tenta desconstruir o mito de Penélope enquanto esposa sempre fiel e paciente. Numa peça de teatro apresentada por Melanto, elas encenam uma suposta conversa que teria ocorrido entre Euricleia e Penélope, na qual a serva vem prevenir sua ama acerca do retorno de Ulisses. Penélope pergunta a Euricleia quem sabe que ela não resistiu aos pretendentes e a serva aponta as doze. Ao que Penélope responde:

\author{
Penélope: \\ [...] Acuse as escravas de libertinas e desleais, \\ Apanhadas pelos pretendentes como indevidas presas, \\ Conspurcadas, vergonhosas, inadequadas \\ Para servir a um senhor magnífico como ele! \\ Euricleia: \\ Vamos calar-lhes as bocas, mandá-las ao Hades - \\ Ele as tratará como vigaristas que são! \\ Penélope: \\ E eu manterei minha fama de esposa honesta - \\ Todos os maridos olharão para ele, o bem-sucedido! \\ (ATWOOD, 2005b, n. p.).
}

Ao destronar Odisseu do lugar de personagem principal de uma narrativa épica em terceira pessoa e escolher dar voz narrativa, em primeira pessoa, a Penélope e abrir espaço para os poemas e encenações das servas, Margaret Atwood rompe com a linguagem épica distante e sagrada da epopeia. Ao mesmo tempo, ela reinterpreta e reavalia a tradição. Ela desmistifica a lenda e oferece, em seu lugar, a experiência pessoal dessas personagens. Ela atualiza o passado absoluto, perfeito e completo do mundo épico e mostra como a Odisseia é só a versão que prevaleceu dentre todos os mitos orais que circulavam - objetivo que ela declara desde a introdução do romance: "a Odisseia, de Homero, não é a única versão da história. O material mítico era originalmente oral e também local - um mito é relatado de um jeito num lugar e de modo bem diferente em outro" (ATWOOD, 2005b, n.p.). Nesse processo, a autora chama a atenção para a relação existente entre a versão homérica da Odisseia e o mundo que a instituiu enquanto cânone e que - enquanto uma das principais narrativas fundadoras desse mesmo cânone - a obra de Homero ajudou a formar.

"Tem-se discutido muito hoje sobre a influência que os mitos e as imagens das mulheres têm sobre todos nós que somos produtos da cultura”, afirma 
Adrienne Rich em "When We Dead Awaken" (RICH, 1972, p. 21, minha tradução ${ }^{2}$ ). O título do artigo de Rich - tomado de empréstimo do título de uma peça de Henrik Ibsen e do uso que George Bernard Shaw faz da expressão em um comentário sobre a peça - exprime exatamente o status de Penélope e suas servas. As narradoras e progonistas do romance de Atwood são, literalmente, como antecipou Shaw em sua resenha, as mortas que acordaram de seu sono eterno para, agora - liberadas, pela morte, do silenciamento que lhes fora imposto em vida -, poderem contar a sua história e apontar por quantos séculos a degradação das mulheres, para usarmos um termo de Rich, vem sendo naturalizado em epopeias, poemas, peças de teatro e histórias que tanto contribuem para a manutenção dos mitos sobre comportamentos esperados e espaços próprios das mulheres.

Sobre silêncios e espaços, Michelle Perrot (2005) aponta em As mulheres ou o silêncio da história que, mesmo que, a partir do século XIX, a presença e a fala femininas tenham começado a irromper em espaços antes proibidos, persistiram "muitas zonas mudas" em nossa sociedade. Essa mudez é ainda mais evidente quando nos voltamos para o passado, que permaneceu "um oceano de silêncio" resultante da "partilha desigual dos traços, da memória [...] e da História, que, por muito tempo, 'esqueceu' as mulheres, como se, [...] elas estivessem fora do tempo, ou ao menos fora do acontecimento" (PERROT, 2005, p. 9).

Esse silenciamento das mulheres, a luta contra ele, a questão da voz é uma das questões principais de A Odisseia de Penélope. É contra esse oceano de silêncio que as vozes de Penélope e suas doze servas se levantam. No primeiro capítulo de sua Odisseia, por exemplo, Penélope contrasta a atitude que ela tinha em vida, a respeito de seu marido e das histórias que eram contadas sobre ele e sobre ela, com a atitude que ela toma agora depois de tantos anos morta. Em vida, ela diz que

Fingia não ver nada. Ficava de boca fechada; ou, se abrisse, só elogiava. Não refutava, não fazia perguntas inconvenientes, não me aprofundava. Queria finais felizes naquela época, e os finais felizes são alcançados quando mantemos certas portas trancadas e dormimos na hora da confusão (ATWOOD, 2005b, n. p.).

Contudo, agora que "todos os outros perderam o fôlego", ela afirma,

É a minha vez de fazer o relato. Devo isso a mim mesma [...]. Contar histórias é uma arte menor [...], mas a essa altura não me importo mais com a opinião pública [...], de quem está aqui: das sombras, dos ecos. Portanto, vou tecer minha própria narrativa.

A dificuldade é não ter boca pela qual falar (ATWOOD, 2005b, n. p.).

"O silêncio", afirma Perrot, a ausência de boca, "é o comum das mulheres", "convém à sua posição subordinada e secundária”. A postura normal das mulheres é a escuta, a espera, o guardar as palavras no fundo de si mesmas" (PERROT, 2005, p. 9). Silenciadas em sua época, proibidas de falar em vida, cansadas de esperar, escutar e de guardar as palavras no fundo de si mesmas, Penélope e suas servas levantam suas vozes, articulam-se coletivamente, como celebra Adrienne 
Rich em seu artigo e contam suas histórias. É claro que essa articulação coletiva não implica na unificação ou na reconciliação de seus objetivos e preocupações, enunciados dialogicamente em sua individualidade na narrativa. Além disso, é só depois de mortas que Penélope e as servas obtêm o poder de re-visar seu passado.

"Re-visão", Rich define, "o ato de olhar para trás, de ver com novos olhos, de entrar em um texto antigo a partir de uma nova direção crítica - é para nós [mulheres] mais do que um capítulo na história cultural: é um ato de sobrevivência" (RICH, 1972, p. 18, minha tradução ${ }^{3}$ ). Na versão de Atwood, Penélope se recusa a continuar sendo usada como um exemplo que cria condições para que mais mulheres sejam oprimidas ao ter seu comportamento medido pelo dela, como tem ocorrido desde a antiguidade até hoje. Ainda nesse primeiro capítulo, ela pergunta:

Não fui fiel? Não esperei, e esperei, e esperei, apesar da tentação - quase compulsão - de desistir? E o que me restou, quando a versão oficial se consolidou? Ser uma lenda edificante. Um chicote para fustigar outras mulheres. Por que não podem todas ser tão circunspectas, confiáveis e sofredoras como eu? Era essa a abordagem que adotavam os cantores, os rapsodos. Não sigam o meu exemplo, sinto vontade de gritar nos ouvidos de vocês - sim, nos de vocês! (ATWOOD, 2005b, n. p.).

Novamente, Penélope alude às muitas histórias que existiam e conviviam na época, e ao processo de consolidação da narrativa oficial, cuja versão dos fatos precisa ser suplementada, ironizada, subvertida em seu nome e em nome das mulheres de hoje. A re-visão do passado, argumenta Rich, é de extrema importância para as vidas das mulheres. "Precisamos conhecer os escritos do passado, e conhecê-los de modo diferente do que jamais conhecemos; não para passar uma tradição adiante, mas para quebrar seu domínio sobre nós" (RICH, 1972, p. 19, minha tradução).

Contudo, na introdução de Survival: a thematic guide to Canadian literature, guia/ manifesto/antologia crítica da literatura canadense publicado por Atwood em 1972, publicação que demonstra o interesse da autora pela questão do cânone desde os anos 1970 e o papel que ela desempenha na construção da ideia de uma literatura canadense, Margaret Atwood afirma que "uma tradição não existe necessariamente para nos enterrar: ela também pode ser usada como material para novas partidas" (ATWOOD, 2012, p. xxi, minha tradução ${ }^{4}$ ). Trinta anos depois das contribuições teóricas de Adrienne Rich, é com essa atitude que Atwood relê Homero. Seu objetivo parece não ser o de oferecer a versão definitiva, mais verdadeira, do que realmente se passou na antiguidade clássica. Ela não exprime nenhum desejo de passado absoluto, muito pelo contrário. Ela reescreve para mostrar que toda história - mesmo a Odisseia - é sempre contada a partir de um ponto de vista e que sempre há uma relação de poder exercida através dos pontos de vista de toda e qualquer narrativa. Tanto que sua própria Odisseia conta com a presença subversiva de uma linha de coro, que abala a confiança que os leitores possam criar na perspectiva apresentada por Penélope, assim como as convenções da forma do romance. 
Esse retorno a Homero pode ser importante, sobretudo para uma escritora mulher canadense contemporânea, uma vez que "nenhum poeta, nenhum artista de nenhuma arte, tem seu significado completo sozinho" (ELIOT, 1982, p. 37, minha tradução ${ }^{5}$ ). "O essencial são os intercessores. A criação são os intercessores. Sem eles não há obra”, declara Gilles Deleuze. E continua:

Fictícios ou reais, animados ou inanimados, é preciso fabricar seus próprios intercessores. É uma série. Se não formamos uma série, mesmo que completamente imaginária, estamos perdidos. Eu preciso de meus intercessores para me exprimir, e eles jamais se exprimiriam sem mim: sempre se trabalha em vários, mesmo quando isso não se vê (DELEUZE, 1992, p. 156).

Com A odisseia de Penélope, Margaret Atwood se insere em uma série e planta a diferença através da repetição. Ela estabelece diálogo com a literatura clássica e com os mitos homéricos, que constituem referência, intertexto e fonte de inspiração e admiração comum a uma larga tradição de autores canônicos da literatura inglesa desde a Renascença - de elizabetanos a modernistas: de Spenser a Pope, de Tennynson a Joyce (CHENEY; HARDIE, 2015; MILES, 1999). É a essa linhagem que ela se filia com diferença, a partir de um novo ponto focal, a partir de um ato de dissidência da tradição, que, simultaneamente, reforça seu vínculo a essa mesma tradição.

Para se inserir nessa série, Atwood parodia a voz de Homero. "A paródia intertextual de clássicos americanos e europeus", define Linda Hutcheon, em The Poetics of Postmodernism, "é um modo de apropriação e reformulação - com uma mudança significativa - da visão branca, masculina, classe média, heterossexual e eurocêntrica da cultura dominante" (1988a, minha tradução ${ }^{6}$ ). A paródia não rejeita a cultura dominante, pois reconhece que não pode. Ela sabe que textos são sempre feitos de outros textos. Então, ela se instala na tradição para subvertê-la de dentro. "O pós-moderno sinaliza sua dependência através de seu uso do cânone, mas revela sua rebelião através do abuso irônico que também faz dele” (HUTCHEON, 1988a, p. 130, minha tradução, grifos da autora ${ }^{7}$ ).

Aqui, a questão da morte retorna. Assim como é a morte que permite Penélope e suas servas contar suas histórias, é a morte de Homero enquanto autor que autoriza que Atwood, Penélope e as doze servas assumam o controle da narrativa, se apropriem do mito, usem e abusem do original. Em sua versão de a Odisseia, como o autor bakhtiniano, Atwood participa do diálogo em isonomia com suas personagens, atuando como uma espécie de regente do coro de vozes que participa do diálogo do romance, cuidando para que cada uma dessas vozes seja ouvida em sua singularidade. A função de autora de Atwood, sua responsabilidade autoral - como ela mesma defende em uma citação que veremos mais à frente neste texto - é absolutamente indispensável para a arquitetura de seu romance (BAKHTIN, 2010). Contudo, é só a partir da morte de Homero enquanto autor - único autor, cuja personalidade genial foi capaz de produzir obras tão grandiosas e perfeitas como a Ilíada e a Odisseia, gênio em cujo altar todos os autores se imolam, conforme discute Friedrich Nietzsche (2010) em "Homero e a filologia clássica” - que Margaret Atwood pôde escrever a sua versão dessa história. 
Quando falamos que Atwood mata Homero, nos referimos à morte do autor tal como ela é debatida por Roland Barthes (2004) e Michel Foucault (2001). Em "A morte do autor", Barthes argumenta que "o autor é uma personagem moderna, produzida sem dúvida pela nossa sociedade". Ele relaciona o contexto de produção do autor ao fim da idade Média, "com o empirismo inglês, o racionalismo francês e a fé pessoal na reforma", momento histórico no qual nossa sociedade "descobriu o prestígio pessoal do indivíduo, [...] da 'pessoa humana". Em se tratando de literatura, ele complementa, foi "o positivismo, resumo e desfecho da ideologia capitalista, que concedeu a maior importância à 'pessoa' do autor”. Dessa forma, a noção do autor enquanto gênio seria um produto histórico do nosso tempo, ausente em outros tempos e espaços, em tempos anteriores à idade Média na sociedade europeia, por exemplo, ou em outros espaços, tais como aqueles das por ele nomeadas "sociedades etnográficas" (BARTHES, 2004, p. 58).

Barthes segue sua argumentação, comentando sobre como, na França de sua época, o "império do Autor" era ainda muito poderoso. Seja "nos manuais de história literária, nas biografias de escritores, nas entrevistas das revistas" ou na "consciência dos literatos", seu reinado permanecia imaculado. O domínio do Autor também era promovido por grande parte da crítica literária, sempre em busca da "explicação da obra", sua decifração, que se daria a partir da revelação da identidade daquele que a produziu, o Autor, repositório da verdade essencial que a Obra encerra, fonte do único significado possível do texto (BARTHES, 2004, p. 58-59).

Em “O que é um autor?", conferência escrita em 1969 e proferida em 1970 na Universidade de Búfalo, Michel Foucault expande as considerações de Barthes e problematiza as questões de autor e obra. Citando uma frase de Samuel Beckett "Que importa quem fala, alguém disse que importa quem fala" -, Foucault argumenta que, a partir de um certo momento da arte modernista europeia e de sua crítica, alguns artistas e críticos objetivavam o apagamento de traços do sujeito do autor na obra. Em seus trabalhos, esses autores a que ele se refere despistavam "todos os signos de sua individualidade particular", faziam "papel de morto no jogo da escrita", visavam "a abertura de um espaço [em sua escrita] onde o sujeito que escreve não para de desaparecer". Esse tal momento da arte também é citado e exemplificado no texto de Barthes. No entanto, apesar de passar longas páginas discorrendo sobre a morte ou o desaparecimento do autor, confrontado ao final de sua fala por Lucien Goldmann, Foucault afirma que, com suas palavras, ele não quis dizer que o autor não existia, mas que o que lhe interessava nessa discussão era apenas apontar como, a partir desse momento da literatura, era possível depreender e caracterizar essa tal função-autor e o seu papel no jogo da linguagem. Em um trecho anterior, que complementa a questão dos usos metodológicos possíveis dessa tal função-autor, Foucault defende que "talvez seja o momento de estudar os discursos não mais apenas em seu valor expressivo ou suas transformações formais, mas nas modalidades de sua existência”. Em vez de focarmos nos temas ou conceitos operados pelo jogo da função-autor, consideraríamos "os modos de circulação, de valorização, de atribuição, de apropriação dos 
discursos", que "variam de acordo com cada cultura e se modificam no interior de cada uma" dessas culturas (FOUCAULT, 2001, p. 264-298).

É nesse jogo da função-autor que Atwood insere seu romance e suas protagonistas. Como já citamos, ela faz questão de afirmar na introdução de $A$ odisseia de Penélope que "a Odisseia de Homero não é a única versão da história" (ATWOOD, 2005b, n. p.). Ao fazer isso, ela questiona o valor que a sociedade moderna atribuiu ao mito homérico e se apropria dessa história para contá-la à sua maneira. Ao matar Homero enquanto gênio, único autor do maior mito da literatura ocidental, fundador do cânone, bardo em cujo altar todos os grandes autores se imolam, Atwood abre espaço para outras possíveis versões da história. Ao mesmo tempo, ao retomar a Odisseia, ela inscreve sua obra no cânone, mas não sem denunciar a sua suposta universalidade através da ironia e da paródia. Além disso, Atwood se coloca como a autora de A Odisseia de Penélope, assumindo sua responsabilidade autoral e mostrando que importa muito quem fala, quem tem o direito de falar e o poder de ser ouvido.

A morte do autor e a desnaturalização dos mitos são manifestações do que Jean-François Lyotard (1984) chamou de "a condição pós-moderna": a desconfiança das grandes narrativas que atribuem sentido e explicam o funcionamento da nossa sociedade, e que apresentam como verdade universal e transcendente aquilo que, na verdade, é socialmente construído e carregado de ideologia.

Para Hutcheon, literatura pós-moderna é aquela que é "abertamente consciente do fato de que ela é escrita e lida como parte de uma cultura específica, tendo tanto em comum com o passado literário quanto com o presente social". O uso que essa literatura faz da "paródia para ecoar trabalhos do passado sinaliza sua percepção de que a literatura é feita, antes de mais nada, de outras literaturas". $\mathrm{Na}$ arte pós-moderna, a metalinguagem e a reflexividade modernista se tornou, paradoxalmente, um meio para "um novo engajamento ao mundo histórico e social” (HUTCHEON, 1988b, p.1, minha tradução ${ }^{8}$ ). Em The Canadian Postmodern, ela explica que, por volta dos anos setenta e oitenta, "o que o resto do mundo começou a chamar de 'pós-modernismo' tinha chegado ao Canadá - mas a forma que ele tomou foi uma forma distintivamente canadense" (HUTCHEON, 1988b, p.1, minha tradução). Segundo ela, foi o próprio momento da história cultural canadense que pareceu "torná-lo pronto para os paradoxos do pós-modernismo" (HUTCHEON, 1988b, p.3, minha tradução). O Canadá é uma nação muito grande que tem pouco senso de um centro geográfico firme (onde ficaria esse centro, brinca Hutcheon: na Inglaterra? Nos Estados Unidos? Em Ontario?). A articulação da identidade nacional canadense pode ser caracterizada como tendo partido de impulsos regionalistas: de Québec, das províncias marítimas, do Oeste. Sua condição é, portanto, fronteiriça, caráter que lhe permite paradoxalmente reconhecer o centro e desafiá-lo ao mesmo tempo (HUTCHEON, 1988b).

Hutcheon também afirma que a condição das escritoras mulheres em geral e dos escritores canadenses é muito semelhante na medida em que em ambos os casos há a necessidade de um "desafio autodefinidor das tradições dominantes (masculina; britânica/americana)". Só se pode negar a "subjetividade" depois de 
já tê-la afirmado, e, curiosamente, na tradição liberal humanista ocidental, essa subjetividade tende a ser definida "em termos de racionalidade, individualidade e poder", "domínios tradicionalmente negados às mulheres, que são relegadas, ao invés disso, aos reinos da intuição, da coletividade familiar e da submissão" (HUTCHEON, 1988b, p. 5, minha tradução). Dessa forma, ambos, canadenses e mulheres, "precisam voltar à sua história para descobrirem (antes de poderem contestar) seus mitos históricos" (HUTCHEON, 1988b, p. 6, minha tradução). É o uso da paródia que os permite questionar os mitos e as formas canônicas das literaturas europeia e americana, desafiando seu status e poder, explorando e subvertendo sua inegável autoridade cultural, assim como a noção liberal-humanista "da arte como original e única" (HUTCHEON, 1988b, p. 6-7, minha tradução9).

Como canadense e mulher, Atwood se recusa a permitir que autores neguem sua cumplicidade com as estruturas de poder que podem os sujeitar (HUTCHEON, 1988b). "É mais difícil para uma escritora mulher, nessa sociedade, do que para um escritor homem", afirma Atwood em "The Curse of Eve - Or What I Learned at School", "mas não por conta de algum mistério hormonal inato ou por diferenças espirituais: é mais difícil porque tornaram mais difícil" (ATWOOD, 1979, p. 33, minha tradução ${ }^{10}$ ). Esta declaração não significa que Atwood se considere uma escritora ativista - pelo menos era o que ela dizia em 2010, antes do sucesso mundial de The Handmaid's Tale, que se tornou símbolo de tantas causas feministas ao redor do mundo, nessa nova onda de movimentos feministas globais que vivemos hoje. "Escritores, enquanto escritores, não são propagandistas ou exemplos de tendências sociais ou pregadores ou políticos" (ATWOOD, 2010, n. p., minha tradução ${ }^{11}$ ), ela afirma em "On Being a Woman Writer". E segue dizendo: eles são fazedores de livros, e, a menos que eles saibam fazer livros bem, eles serão escritores ruins, não importa qual seja a validade social de suas opiniões (ATWOOD, 2010, n. p.). O problema, ela afirma, é que a "escrita tende a ser sobre a vida, não como ela deveria ser, mas como ela é, como o escritor a sente, a experimenta. Writers are eye-witnesses, I-witnesses" (ATWOOD, 2010, n. p., minha tradução $0^{12}$ ). Embora não se considere uma escritora feminista ativista, Atwood acha que os escritores não podem se esquivar de seu lugar de responsabilidade autoral:

Por que os autores desejam fingir que eles não existem? É um jeito de se esquivar, de evitar a verdade e suas consequências. Eles gostariam de negar o crime, embora suas digitais estejam por todo o copo de Martini, isso sem falar da serra e do pescoço da vítima. Amnésia, eles alegam. Epilepsia. Overdose de açúcar. Possessão demoníaca. Que conveniente ter um gêmeo autoral, vivendo no seu corpo, olhando através dos seus olhos, pondo a caneta no papel ou apertando a tecla do teclado, enquanto você faz o que? Lixa as unhas? (ATWOOD, 1995, p. 17, minha tradução ${ }^{13}$ ).

Vemos, portanto, através do exame das falas de Atwood e do romance que analisamos neste trabalho, que, para escritoras mulheres, assim como para escritores pós-coloniais, pode ser "muito importante e produtivo fazer as perguntas que o texto não incita a fazer sobre ele": analisar como ele "se relaciona com 
outros textos e com outras práticas; o que oculta ou reprime; o que afirma ou do que é cúmplice" como afirma Jonathan Culler em seu artigo "Em defesa da superinterpretação" (CULLER, 2005, p. 136). Em outro trecho deste mesmo artigo, esse autor afirma que "muitas das formas mais interessantes da crítica moderna não perguntam o que a obra tem em mente, mas o que ela esquece, não o que ela diz, mas o que toma como ponto pacífico" (CULLER, 2005, p. 136-137). Culler estava falando do papel da crítica em seu texto, mas poderia estar falando da obra de Atwood, ou, como já vimos o porquê, de muitas obras canadenses pósmodernas. De sua posição reflexiva pós-moderna, é este o papel que A Odisseia de Penélope assume.

\section{Notas}

1. No original: "Myths are universal and timeless stories that reflect and shape our lives - they explore our desires, our fears, our longings, and provide narratives that remind us what it means to be human" (ABOUT..., s.l, n/p).

2. No original: "A lot is being said today about the influence that the myths and images of women have on all of us who are products of culture" (RICH, 1972, p. 21).

3. No original: "Re-vision-the act of looking back, of seeing with fresh eyes, of entering an old text from a new critical direction-is for us more than a chapter in cultural history: it is an act of survival" (RICH, 1972, p. 19).

4. No original: "a tradition doesn't necessarily exist to bury you: it can also be used as material for new departures" (ATWOOD, 2012, p. xxi).

5. No original: "No poet, no artist of any art, has his complete meaning alone" (ELIOT, 1982, p. 37).

6. No original: "Intertextual parody of canonical American and European classics is one mode of appropriating and reformulating - with significant change the dominant, white, male middle-class, heterosexual, Euro-centric culture" (HUTCHEON, 1988a).

7. No original: "Postmodernism signals its dependence by its use of the canon, but reveals its rebellion through its ironic abuse of it" (HUTCHEON, 1988a, p. 130, grifos da autora).

8. No Original: "What the rest of the world was starting to call 'postmodernism' had arrived in Canada - but the form I took was a distinctively Canadian one. [...] From what I can gleam from the usage of the term, 'postmodernism' would seem to designate art forms that are fundamentally self-reflexive - in other words, [...] literature that is openly aware of the fact that it is written and read as part of a particular culture, having as much to do with the literary past as with the social present. Its use of parody to echo past works signals its awareness that literature is made, first and foremost, out of other literature. But there is a problem with this definition: it could also be a description of the earlier modernist art of the beginning of the century, with its belief in the autonomy and self-sufficiency of the art object. The continuity between the modernist and the postmodernist is a very real one, but what distinguishes them, I would argue, is that in the postmodern this selfconsciousness of art as art is paradoxically made the means to a new engagement with the social and the historical world" (HUTCHEON, 1988b, p. 1-3). "However, Canada's own particular moment does seem to make it ripe for the paradoxes of postmodernism [...] (p.3)"

9. No original: "Though four and a half centuries apart in time and of different genders, the woman and the Canadian find that they have much in common. [...] I know I 
am not alone in suggesting a parallel analogy here between the position of woman writers (anywhere) and Canadian writers working in English. In both cases there is a necessary self-defining challenging of the dominant traditions (male; British/ American). What Stan Fogel calls Atwood's obsession with 'character formation and the difficulty of maintaining ontological security' $(p .116)$ is also true of much fiction written by women today, and the reason is an obvious one - and it is not that women writers are by nature more conservative and traditionally realist. The reason is that you can assume selfhood ('character formation') or 'subjectivity' only when you have attained it. Subjectivity in the Western liberal humanist tradition has been defined in terms of rationality, individuality, and power, in other words, it is defined in terms of those domains traditionally denied women, who are relegated instead to the realms of intuition, familial collectivity and submission. [...] Like women writers in general, Canadian novelists must return to their history $[. .$.$] in order to$ discover (before they can contest) their historical myths. [...] Through the use of parody they have also contested the canonical myths and forms of European and American literatures [...] In so doing they also challenge related liberal-humanist notions of art as original and unique, notions that are tied up with (male) notions of individual subjectivity. And they often do so by means of parody: by first recalling the (male; British/American) canonical texts of our culture, both 'high' and popular, and then challenging them by undoing their status and power" (HUTCHEON, 1988b, p. 5-8).

10. No original: "It is more difficult for a woman writer in this society than for a male writer. But not because of any innate mysterious hormonal or spiritual differences: it is more difficult because it has been made more difficult" (ATWOOD, 1979, p. 33).

11. No original: "Writers, as writers, are not propagandists or examples of social trends or preachers or politicians. They are makers of books, and unless they can make books well they will be bad writers, no matter what the social validity of their views" (ATWOOD, 2010, n. p.).

12. No original: "Writing, however, tends to concentrate more on life, not as it ought to be, but as it is, as the writer feels it, experiences it. Writers are eye-witnesses, I-witnesses" (ATWOOD, 2010, n. p.).

13. No original: "Why do authors wish to pretend they don't exist? It's a way of skinning out, of avoiding truth and consequences. They'd like to deny the crime, although their fingerprints are all over the martini glasses, not to mention the hacksaw blade and the victim's neck. Amnesia, they plead. Epilepsy. Sugar overdose. Demonic possession. How convenient to have an authorial twin, living in your body, looking out through your eyes, pushing pen down on paper or key down on keyboard, while you do what? File your nails?" (ATWOOD, 1995, p. 17).

\section{Referências}

ABOUT the Myths. The Myths. UK: Canon Gate. Disponível em: https://web.archive. org/web/20141225072917/http://www.themyths.co.uk/ Acesso em: 30 jul. 2020.

ATWOOD, M. A odisseia de Penélope. Tradução de Celso Nogueira. Companhia das Letras, 2005b. Edição Kindle.

ATWOOD, M. On Being a "Woman Writer". This Recording, 2010. Disponível em: http://thisrecording.com/today/2010/8/29/in-which-we-change-diapers-andcollect-china.html. Acesso em: 30 jul. 2020.

ATWOOD, M. Survival. Toronto: House of Anansi Press Inc., 2012.

ATWOOD, M. The Curse of Eve - Or, What I Learned at School. Canadian Woman Studies / Les cahiers de la femme, v. 1, n. 3, p. 30-33, 1979. 
ATWOOD, M. The Myth Series and Me: Rewriting a classic is its own epic journey. Publisher's Weekly. 28 nov. 2005a. Disponível em: https://www.publishersweekly. $\mathrm{com} / \mathrm{pw} /$ by-topic/columns-and-blogs/soapbox/article/37037-the-myths-seriesand-me.html. Acesso em: 30 jul. 2020.

ATWOOD, M. In: HALPERN, D. (ed.). Who's writing this? Notations on the Authorial I with Self-portraits. New Jersey: Ecco Press, 1995.

BARTHES, R. Mitologias. Tradução de Rita Buongermino e Pedro de Souza. Rio de Janeiro, Bertrand Brasil, 2001.

BARTHES, R. O rumor da língua. Tradução de Mario Laranjeira. Revisão da Tradução de Andréa Stahel. São Paulo: Martins Fontes, 2004.

BAKHTIN, M. Epos e romance. In: BAKHTIN, M. Questões de literatura e estética: a teoria do romance. Tradução de Aurora Bernardini et al. São Paulo: Hucitec, 1993. p. 397-428.

BAKHTIN, M. Problemas da poética de Dostoiévski. Tradução de Paulo Bezerra. Rio de Janeiro: Forense Universitária, 2010.

CHENEY, P. \& HARDIE, P. (ed.). The Oxford History of Classical Reception in English Literature: Volume 2 (1558-1660). Oxford: Oxford University Press, 2015.

CULLER, J. Em defesa da superinterpretação. In: ECO, Umberto. Interpretação e superinterpretação. Tradução MF. Revisão da Tradução Monica Stahel. São Paulo: Martins Fontes, 2005. p. 129-146.

DELEUZE, G. Conversações. Tradução de Peter Pál Pelbart. São Paulo: Editora 34, 1992.

ELIOT, T. S. Tradition and the Individual Talent. Perspecta, v. 19, p. 36-42, 1982.

FOUCAULT, M. O que é um autor?. In: FOUCAULT, M. Ditos e escritos: estética literatura e pintura, música e cinema (vol. III). Tradução de Inês Autran Dourado Barbosa. Rio de Janeiro: Forense Universitária, 2001. p. 264-298

HOMERO. Odisseia. Tradução de Frederico Lourenço. São Paulo: Penguin Companhia das Letras, 2013.

HUTCHEON, L. A Poetics of Postmodernism. Londres: Routledge, 1988a.

HUTCHEON, L. The Canadian Postmodern. Oxford: Oxford University Press, 1988b.

LYOTARD, J. The Postmodern Condition: A Report on Knwoledge. Tradução de Geoff Bennington e Brian Massumi. Minneapolis: University of Minnesota Press, 1984.

MILES, G. (ed.). Classical Mythology in English Literature: A Critical Anthology. Londres e Nova York: Routledge, 1999.

NIETZSCHE. F. Homero e a filologia clássica. Tradução, apresentação e notas de Juan A. Bonaccini. Princípios: Revista de Filosofia, Natal, v. 13, n. 19-20, p.169199, 26 set. 2010.

PERROT, M. As mulheres ou os silêncios da história. Tradução de Viviane Ribeiro. Bauru: EDUSC, 2005.

RICH, A. When We Dead Awaken: Writing as Re-Vision. In: College English, Vol. 34, No. 1, Women, Writing and Teaching, p. 18-30, out. 1972.

Recebido em: 30/07/2020 Aceito em: 17/09/2020 